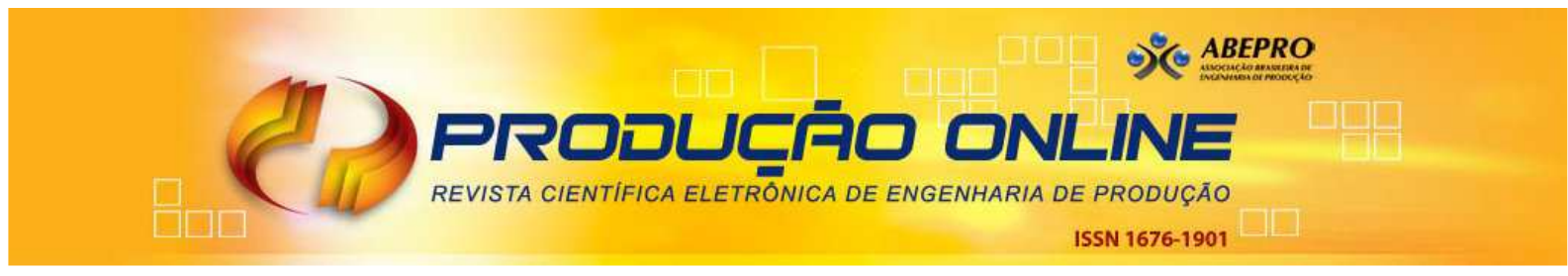

\title{
ANÁLISE DE REDES SOCIAIS NA INDÚSTRIA FARMACÊUTICA: UM ESTUDO COM FARMÁCIAS E DROGARIAS
}

\section{SOCIAL NETWORK ANALYSIS IN THE PHARMACEUTICAL INDUSTRY: A STUDY OF PHARMACIES AND DRUGSTORES}

\author{
Moacyr Cortelette Junior* E-mail: moacyr.cortelette@gmail.com \\ Teresa Cristina Janes Carneiro* E-mail: carneiro.teresa@gmail.com \\ *Universidade Federal do Espírito Santo
}

\begin{abstract}
Resumo: O objetivo desse estudo foi, a partir do mapeamento da integração de dados entre farmácias e drogarias, visualizar os efeitos da tecnologia da informação na formação de redes sociais e verificar se os laços sociais motivam a formação de um ambiente colaborativo entre empresas que competem entre si no setor. Foram realizadas entrevistas e observação direta em 66 drogarias e farmácias em 11 bairros de Vila Velha/ES. Para o mapeamento e análise da rede social, foi utilizado o software UCINET. Das empresas estudadas, 48 estão conectadas a uma rede social de relacionamentos tanto formal quanto informal, por meio da qual a informação pode fluir potencializando a comunicação e a integração no setor. Das empresas mais isoladas, $66,67 \%$ são farmácias, indicando uma tendência de não integração à rede social em comparação com drogarias. A densidade calculada da rede social foi de $4,2 \%$, refletindo a existência de componentes com número reduzido de vértices. Se considerada apenas a componente principal, a densidade sobe para $7,62 \%$, indicando que a densidade da rede social pode ser aumentada caso haja esforço dos atores da componente principal em integrar as demais componentes. Observou-se a existência de ampla gama de conexões possíveis que, se forem estabelecidas, podem ajudar a reduzir a fragilidade da rede social.
\end{abstract}

Palavras-chave: Análise de redes sociais. Integração. Indústria farmacêutica. Redes de empresas. UCINET.

\begin{abstract}
The purpose of this study is, by data integration mapping among pharmacies and drugstores, identify the effects of Information Technologies on social networks building and check if the social ties promote an environment of collaboration, even among firms that compete in the industry. Interviews and in locus observation were made in 66 drugstores and pharmacies from 11 districts of Vila Velha/ES. The social network analysis (SNA) was made using the software UCINET. Among the companies studied, 48 are connected through a social network of both formal and informal relationships, in which information can flow enhancing communication and integration in the industry. Pharmacies represent $66.67 \%$ of the most isolated companies, which indicates a trend of not belonging to the network compared to drugstores. The social network density was $4.20 \%$, reflecting the existence of isolated vertices and components with a small number of vertices. If it was considered only the main component, the density rises to $7.62 \%$, signaling that the social network density can be increased if the actors of the main component make enough effort to integrate the others. However, there is a wide range of possible connections that have not been established and that can help reduce the social network fragility.
\end{abstract}

Keywords: Social network analysis. Integration. Pharmaceutics industry. Enterprise networks. UCINET. 


\section{INTRODUÇÃO}

As tecnologias de informação e comunicação (TIC) possuem um papel fundamental na denominada indústria farmacêutica, dada a necessidade de constante padronização, controle e atualização das informações do setor. O barateamento das TIC (hardware e software), juntamente com a popularização da internet, tornou possível a construção de uma rede integradora de informações entre os vários participantes da indústria. Desse modo, organismos de controle e regulamentação, centros de pesquisa, fornecedores de matéria-prima, laboratórios, distribuidores, hospitais, clínicas, farmácias, drogarias e até mesmo o consumidor final podem estar interligados por uma rede que compartilha informações em tempo real, possibilitando o aumento da eficiência logística e da qualidade do serviço prestado.

Diversos fatores forçaram farmácias e drogarias a adaptar-se e a contratar soluções em TICs para garantir o atendimento às exigências normativas e às necessidades dos consumidores. Entre esses fatores podem-se citar consumidores cada vez mais informados e exigentes, crescente produção de medicamentos, distribuidores capazes de atender em todo território nacional, exigências de controle e fiscalização por parte do governo e o aumento da concorrência. Softwares com soluções integradas para gestão financeira, atendimento customizado, pedido eletrônico de mercadorias, entre outras funções, tornaram-se comuns nesses estabelecimentos comerciais.

A utilização das TICs, mais frequente nas distribuidoras, passou a atingir também o comércio varejista de forma integrada. Principalmente nas microempresas, os esforços relacionados à adaptação do negócio às exigências em TICs são expressivos, envolvendo significativos investimentos em aquisição de equipamentos e softwares e treinamento de pessoal - que muitas vezes não ocorre de forma adequada, podendo gerar a subutilização dos recursos de TICs adquiridos.

Estudar a integração de dados no setor farmacêutico justifica-se por ser uma tentativa de entender a dinâmica das TICs aplicadas ao setor e os principais desafios e problemas enfrentados, temática em contínua evolução e que pode contribuir para a melhoria das ferramentas existentes, tornando-as mais eficientes e 
mais adequadas às necessidades do setor. Para isso, optou-se por investigar como as TICs têm influenciado a formação de redes sociais entre drogarias e farmácias e com que intensidade essas redes sociais promovem a colaboração no setor e uma melhoria na qualidade do atendimento ao consumidor final.

O objetivo desse estudo é compreender os efeitos das TICs na formação de redes sociais entre farmácias e drogarias. Partiu-se da suposição de que os laços sociais transcendem os limites impostos pela concorrência e, potencializados pelas TICs, motivam a formação de um ambiente colaborativo entre empresas que competem no mercado.

\section{PROCEDIMENTOS METODOLÓGICOS}

Por meio da experiência profissional no setor de um dos pesquisadores e baseando-se em pesquisa bibliográfica sobre características organizacionais, integração de dados, aplicação das TICs e formação de redes sociais no setor farmacêutico, elaborou-se a suposição de que os laços sociais estabelecidos com auxílio dessas tecnologias transcendem os limites impostos pela concorrência e motivam a formação de um ambiente colaborativo entre empresas que competem no mercado.

Foram realizadas entrevistas semi-estruturadas e ações de observação direta de caráter exploratório em 66 drogarias e farmácias do município de Vila Velha, no Estado do Espírito Santo, visando a elucidar a suposição elaborada. A amostra foi selecionada adotando-se uma abordagem mista, tanto geográfica quanto intuitiva, e guiada pela técnica denominada "bola-de-neve" (KNOKE, 2008, p. 18). A figura 1 ilustra a demarcação geográfica para os limites da pesquisa e a área onde se estima que aproximadamente 100 farmácias e drogarias estejam instaladas, podendo esse número variar para mais ou menos devido à dinâmica de abertura e fechamento de empresas nos 11 bairros pesquisados.

O mapeamento das empresas da região foi feito por meio da tecnologia googlemaps e do software Google Earth (GOOGLE..., 2009), por meio de lista telefônica online (TELELISTAS.NET, 2010) e pelo pesquisador que percorreu as principais ruas e avenidas dos bairros pertencentes à região escolhida. Utilizando a técnica "bola-de-neve", o pesquisador partiu da drogaria na qual trabalhou e seguiu investigando, sempre que possível e de acordo com a acessibilidade, as demais 
drogarias e farmácias com as quais a primeira estabelece contato. $O$ contato considerado foi indicado por cada estabelecimento, que levou em conta as outras principais empresas com as quais troca informações sobre o setor ou faz algum tipo de parceria comercial. Esses contatos são estabelecidos tanto pelos proprietários quanto pelos demais empregados das empresas. A cada novo estabelecimento 0 processo foi repetido sempre respeitando os limites geográficos escolhidos.

Figura 1 - Visão aérea de bairros de Vila Velha, Espírito Santo. (a) limites geográficos escolhidos para a pesquisa; (b) estimativa e localização de farmácias e drogarias na região

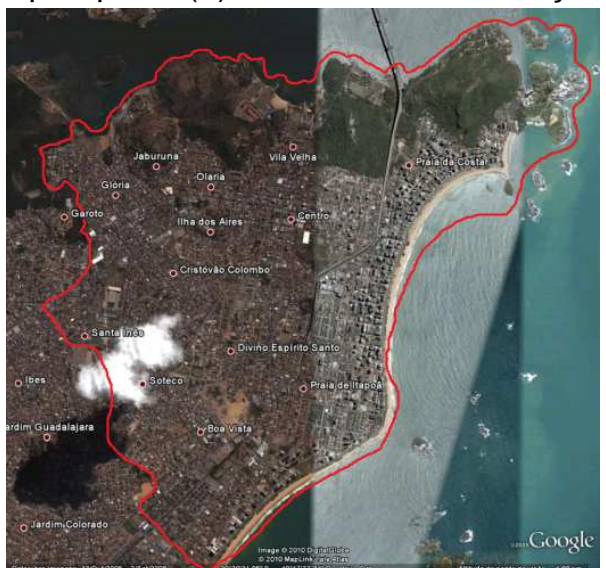

(a)

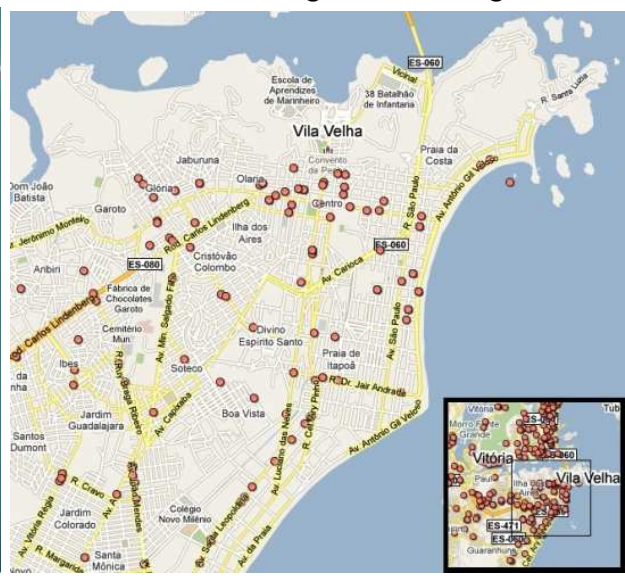

(b)

Fonte: Google Earth (2009)

Tabela 1 - Quantidade e porcentagem de empresas por bairros pesquisados.

\begin{tabular}{lcc}
\hline Bairros & Frequência Absoluta & Frequência Relativa [\%] \\
\hline Itapoã & 11 & 16,67 \\
Divino E. Santo & 1 & 1,52 \\
Cristóvão Colombo & 3 & 4,55 \\
Santa Mônica & 2 & 3,03 \\
Centro & 17 & 25,76 \\
Itaparica & 9 & 13,64 \\
Praia da Costa & 9 & 13,64 \\
Prainha & 1 & 1,52 \\
Ataíde & 1 & 1,52 \\
Santa Inês & 4 & 6,06 \\
Glória & 8 & 12,12 \\
\hline Total & 66 & 100,00 \\
\hline
\end{tabular}

Os dados-atributos gerados foram tratados por meio de métodos estatísticos. Os dados relacionais foram analisados utilizando técnicas de análise de redes 
sociais e suas métricas, com o apoio do software de análise de redes sociais UCINET (BORGATTI et al., 2002).

\section{REFERENCIAL TEÓRICO}

\subsection{O Setor Farmacêutico e as TIC}

De acordo com a Lei oㅜ 5.991, de 17 de dezembro de 1973, que dispõe sobre o controle sanitário do comércio de drogas, medicamentos, insumos farmacêuticos e correlatos, drogaria é o estabelecimento de dispensação e comércio de drogas, medicamentos, insumos farmacêuticos e correlatos em suas embalagens originais. Difere-se da farmácia, que é o estabelecimento de manipulação de fórmulas magistrais e oficinais, de comércio de drogas, medicamentos, insumos farmacêuticos e correlatos, compreendendo os insumos de dispensação e os de atendimento privativo de unidade hospitalar ou de qualquer outra equivalente, de assistência médica.

De acordo com o relatório de dezembro de 2009 da comissão de fiscalização do Conselho Federal de Farmácia (CFF, 2010), existem no Brasil 79.010 farmácias e drogarias, 8.284 farmácias públicas, 5.490 farmácias hospitalares, 3.844 distribuidoras de medicamentos e 550 indústrias farmacêuticas. Além das indústrias, distribuidores, farmácias e drogarias a cadeia produtiva da indústria farmacêutica também é composta pelos fornecedores de matéria-prima, hospitais, clínicas e demais centros de saúde e pelos pacientes e consumidores finais. 
Figura 2 - Cadeia produtiva da Indústria Farmacêutica. Fonte: Machline; Amaral Jr (1998)

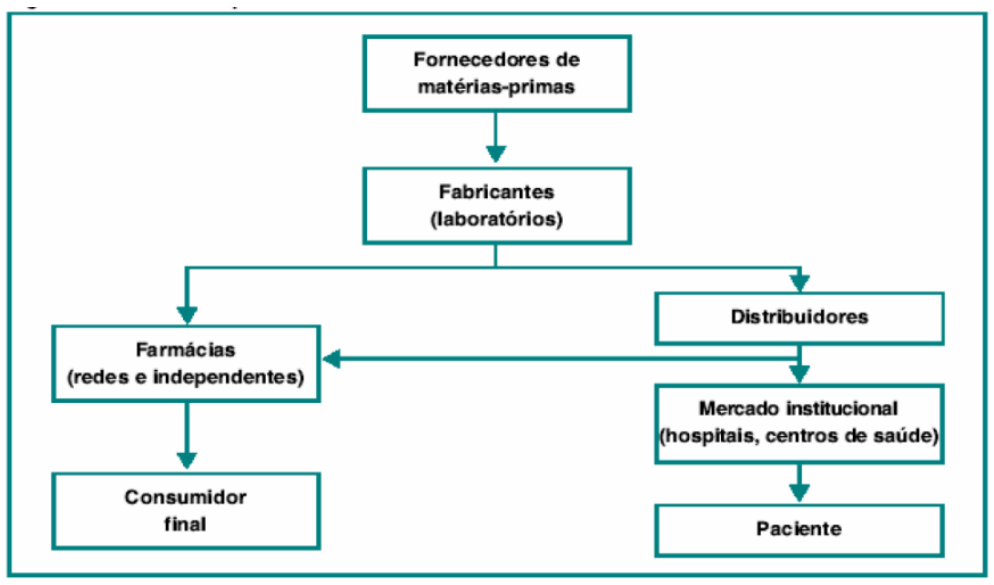

O setor farmacêutico interage ainda com os órgãos de controle e fiscalização, como a Agência Nacional de Vigilância Sanitária (ANVISA) e com fornecedores de soluções em tecnologia de informação. As TICs são indispensáveis no setor, em que há grande giro de produtos e demandas constantes que precisam ser controladas e atendidas em breves intervalos de tempo e com alta precisão.

As farmácias e drogarias são o principal canal de dispensação de remédios para a população brasileira. Segundo o instituto IMS Health (2009), o Brasil é o 4ํㅜㅇ mercado de consumo de medicamentos no cenário mundial e de acordo com o Conselho Federal de Farmácia (CFF, 2010), no Brasil há mais de 60 mil farmácias e drogarias (país com o maior número de farmácias do mundo), com uma proporção de 3,34 farmácias para cada 10 mil habitantes, considerando uma população de 170 milhões de habitantes.

As farmácias e drogarias privadas independentes representam mais de $90 \%$ do total. A maioria não tem bandeira e apenas $6 \%$ atuam sob 0 modelo associativista de gestão empresarial. Por meio desse modelo enfrentam com profissionalismo e poder de barganha as dificuldades do mercado, dominado pelas grandes corporações: reduzem custos, diversificam o número de produtos comercializados, padronizam o layout das lojas e desenvolvem produtos com marcas próprias (FEBRAFAR, 2010).

Muitas redes privadas de farmácias e drogarias optam pela compra de mercadorias do distribuidor em vez de fazê-lo diretamente da indústria, tendo em vista o elevado giro do estoque de seus estabelecimentos e a maior agilidade na 
entrega dos medicamentos. Além disso, o distribuidor atacadista oferece condições de fracionamento de embalagens, o que atende aos pequenos comerciantes (CARNEIRO, 2005, p. 85).

Existem ainda nesse contexto as farmácias populares, criadas pelo governo para ampliar o acesso da população a medicamentos considerados essenciais. Tais medicamentos são vendidos a preço de custo, ou até mesmo a preços inferiores ao custo, para o consumidor que apresenta, no ato da compra, uma receita médica ou odontológica do Sistema Único de Saúde (SUS) ou das empresas privadas. Segundo o Portal Saúde (2010), o programa possui Farmácias Populares próprias e também parceria com farmácias e drogarias privadas, a qual é chamada de Sistema de Co-pagamento ou "Aqui tem Farmácia Popular".

Com diversos canais de distribuição e uma cadeia composta por numerosos agentes, o consumidor brasileiro pode adquirir medicamentos por três meios principais: pelo Sistema Único de Saúde (SUS), de forma gratuita; pelas farmácias populares, a preço de custo ou inferior; ou pelas farmácias e drogarias privadas que, devido à forte concorrência, oferecem descontos, condições de pagamento especiais, serviços de entrega em domicílio e atendimento customizado. Nos estabelecimentos privados é possível observar a oferta de serviços não vinculados à área de saúde, como a comercialização de pilhas e baterias, produtos de gênero alimentício, recarga de celular e cartões telefônicos, além de chinelos e sandálias. Esse tipo de comercialização tem como objetivo atrair clientes e suprir necessidades recorrentes de consumo da região.

As empresas fornecedoras de soluções em tecnologia de informação encontram, nesse cenário, amplo campo de atuação. Elas oferecem mecanismos e alternativas para possibilitar ou agilizar certas ações, tais como: atendimento customizado e eficiente ao consumidor final, o controle logístico da produção, estoque e distribuição de medicamentos, comunicação entre membros do setor, informatização da fiscalização exercida pelos órgãos responsáveis, entre outros.

Essas empresas atuam fornecendo sistemas integrados de gestão (Enterprise Resource Planning - ERP), softwares de pedido eletrônico, centrais de venda por telefone, comunicação digital VoIP (Voice over Internet Protocol), soluções de gerenciamento adaptadas às necessidades das farmácias e drogarias, softwares 
para gestão de relacionamentos com clientes (CRM - Customer Relationship Management), módulos de $\mathrm{BI}$ (Business Inteligence), sistema de apoio à decisão, além de softwares e sistemas para fiscalização e controle, como o SNGPC (Sistema Nacional de Gerenciamento de Produtos Controlados).

A lógica do investimento em TICs em uma cadeia de suprimentos consiste em captar a demanda junto ao consumidor final em tempo tão próximo quanto possível do real (CHRISTOPHER, 1997, p. 174). É essencial que a gestão dessas informações oriente a sua captura e tratamento, de maneira a gerar valor para os usuários, conhecimento para as empresas e beneficiar a cadeia de suprimentos como um todo. O objetivo é a integração interna da organização, mas em conexão eficiente com os seus fornecedores, distribuidores e clientes finais (CHRISTOPHER, 1997, p. 206).

Além disso, a existência de meios de comunicação integradores possibilita a troca de informações e experiências entre os diversos agentes do setor, e cria laços sociais que permitem melhorar a eficiência dos serviços prestados ao consumidor.

Nas empresas, é possível observar um esforço significativo em atrair potenciais clientes e em construir (e manter) um laço social de modo a garantir a fidelização e a maximização dos serviços prestados - e, consequentemente, alavancar a lucratividade.

A intenção é criar uma "via de informação" que ligue o consumidor final a todos os participantes da cadeia (ou rede), possibilitando a obtenção de melhores resultados a custos mais baixos com maior capacidade de resposta. $\mathrm{Na}$ realidade, $\mathrm{o}$ objetivo básico é que as organizações participantes da rede procurem criar valor adicional para o cliente pela troca de informações entre os demais membros (MOORI et al., 2007, p. 81).

Os órgãos de controle e fiscalização, por sua vez, também exigem dos integrantes do setor farmacêutico respostas rápidas e precisas, relacionadas à adequação às normas, ao cumprimento da entrega de relatórios periódicos e ao fornecimento de dados sobre o estabelecimento. Segundo a Anvisa (2009), o SNGPC tornou-se iniciativa modelo na Comissão Interamericana para Controle de Drogas. É uma resposta positiva e inovadora às recomendações da Junta 
Internacional de Fiscalização de Entorpecentes (Jife) sobre o consumo de medicamentos usados para emagrecimento.

O SNGPC é um programa informatizado de captura e tratamento de dados que monitora a produção, circulação, comércio e uso de medicamentos sujeitos a controle especial. Possibilita a transmissão eletrônica de dados via Internet sobre compra, venda, transferência e até perda de medicamentos, com detalhes como médico prescritor, estabelecimento distribuidor, nome e concentração do medicamento, quantidade na embalagem, lote, classe terapêutica, estado físico e unidade de medida dos produtos. É adaptável a qualquer tipo de estabelecimento e condições de operação, bastando, apenas, a existência de um computador com capacidade de conexão e uma linha telefônica. A adoção do sistema no Brasil tornou obrigatória e essencial a utilização das TICs nas farmácias e drogarias que comercializam substâncias controladas (ANVISA, 2009).

\subsection{Análise de Redes Sociais}

Segundo Castells (2000), a predominância das redes no mundo industrializado pós-moderno coloca em xeque categorias e conceitos tradicionais, dentre os quais o individualismo e as relações de poder. Estar em rede associa-se à existência social, política e econômica, assim como à riqueza; por outro lado, o não estar em rede associa-se a antigas e novas formas de exclusão, de miséria e de violência. No mundo em rede, a identidade sofre influência de novos códigos e a vida - como resultado de uma rede de interações de naturezas diversas - é um fluxo que corre em uma velocidade sem precedentes, em um tempo-espaço altamente tecnológico.

Newman et al. (2006) explica que redes, tais como a internet, redes sociais e biológicas de diversos tipos, tem sido tema de intenso estudo no últimos anos. Da física e da ciência da computação à biologia e às ciências sociais, pesquisadores descobriram que uma grande quantidade de sistemas podem ser representados como redes, e que há muito o que se aprender pelo estudo dessas estruturas. O estudo da internet (KLEINBERG, 1999; COHEN et al., 2000; PASTOR-SATORRAS; VESPIGNANI, 2001) e de sistemas de transmissão e comunicação (CALLAWAY et al., 2000; ADAMIC et al., 2001), por exemplo, levou ao desenvolvimento de novos e 
poderosos mecanismos de busca. O estudo de redes sociais proporcionou novas ideias sobre a propagação de doenças (BALL et al., 1997; KEELING, 1999; KUPERMAN; ABRAMSON, 2001) e de técnicas para controlá-la. O estudo de redes metabólicas (ALBERT et al., 2000) ensinou sobre os blocos fundamentais da vida e gerou novas ferramentas para a análise de grandes volumes de dados bioquímicos que estão sendo gerados pelo sequenciamento genético e demais experimentos e técnicas. O autor explica que o estudo das redes possui uma longa história nas ciências e na matemática desde a elaboração do que é considerado o primeiro teorema da teoria de grafos pelo matemático Leonard Euler, em 1736.

Knoke (2008) define rede social como uma estrutura composta por um conjunto de atores, alguns dos quais estão conectados por uma ou mais relações. $\mathrm{Na}$ obra, o autor documenta as principais mudanças que ocorreram no campo da análise de redes sociais nos últimos 25 anos, desde os conceitos básicos até os métodos de análise.

Freeman (2004) relata o histórico de desenvolvimento da análise de redes sociais, a origem das primeiras ideias e conceitos, a evolução da pesquisa nas décadas de 1940, 1950 e 1960, as tentativas de padronização e organização do campo, o desenvolvimento de sistemas computacionais e de softwares de análise de redes sociais, mapeia os principais autores e influenciadores dessa área de pesquisa ao longo dos anos e relata a interdisciplinaridade e a multidisciplinaridade existentes na área. Segundo o autor, a análise de redes sociais é a abordagem estrutural baseada no estudo das interações entre atores sociais. As relações que os analistas da área estudam costumam ser links entre seres humanos; entretanto, esses links podem ligar atores que não são exatamente indivíduos, como, por exemplo, grupos e organizações e até mesmo estados-nações e alianças internacionais. Portanto, pode-se dizer que uma rede social é composta por atores (também chamados de agentes ou nós) e pelas conexões existentes entre eles (chamadas de laços, links ou caminhos). Os agentes podem ser tanto indivíduos quanto grupos ou organizações e as conexões podem ser estabelecidas reciprocamente entre dois agentes ou de modo unidirecional (a informação, ação ou percepção partindo de um agente em sentido único para outro). 
Segundo Knoke (2008, p. 4-6), a importância da análise de redes sociais é definida sobre três pressupostos: i) relações estruturais são frequentemente mais importantes para o entendimento de comportamentos observados do que atributos como idade, gênero, valores e ideologias; ii) redes sociais afetam percepções, crenças e ações por meio de uma variedade de mecanismos estruturais que são socialmente construídos por relações entre entidades. Contatos diretos e interações mais intensas proporcionam às entidades melhores informações, maior conhecimento e maior suscetibilidade a serem influenciadas por pares ou influenciarem as outras. Relações indiretas por intermediários também contribuem para o contato com novas ideias e para o acesso potencial a recursos úteis que podem ser adquiridos por meio de transações com os outros; iii) relações estruturais devem ser vistas como processos dinâmicos uma vez que redes sociais não são estruturas estáticas e estão constantemente mudando devido às interações entre seus constituintes.

Knoke (2008, p. 10-5) também enumera os três elementos da formatação da pesquisa de redes sociais que modelam as medidas e as estratégias de análise disponíveis para os pesquisadores: unidades de amostragem, conteúdo e forma relacional, e nível da análise de dados. Ele explica que, variando a combinação desses três elementos, é possível gerar a ampla gama de investigações em redes sociais as quais aparecem na literatura das várias disciplinas que abordam esse conteúdo. A seleção da amostra é o primeiro passo na formatação de um estudo de análise de redes sociais. Um cenário social relevante deve ser escolhido, e devem ser decididas quais entidades nesse contexto constituem os atores sociais. Indivíduos, grupos (formais ou informais), empresas, classes, comunidades e nações, são algumas das unidades básicas de onde amostras podem ser selecionadas. Estudos podem contemplar dois níveis de investigação: um superior que pode, por exemplo, ser formado por um setor composto por organizações e empresas, e outro inferior, composto pelos agentes que se relacionam nessas organizações e empresas.

Grande número de pesquisas costuma escolher cenários em escala reduzida e tratar os indivíduos existentes como os atores sociais. Cenários reduzidos costumam apresentar vantagens uma vez que é mais fácil definir limites de 
amostras, conseguir acesso aos atores e analisar parcela significativa do grupo que compõe o cenário escolhido. Podem ser utilizadas abordagens geográficas, intuitivas ou estratégias, como o método "bola-de-neve" para delimitar os limites de um cenário. Em particular a análise de redes sociais é mais eficiente quando são considerados o maior número de atores e seus respectivos links com outros atores que compõe um cenário. Amostragens puramente espaciais com a escolha aleatória dos alvos da pesquisa não costumam retratar de forma verossímil a estrutura da rede social estudada.

Os pesquisadores também devem decidir sobre que tipo de relações será utilizado para recolher dados. Existe uma dicotomia forma-conteúdo que se aplica à análise de redes sociais. A forma relacional é a propriedade das relações entre atores que existem independentemente de conteúdos específicos. Duas formas relacionais básicas são: i) a intensidade, frequência ou força das interações entre pares de atores; ii) a direção das relações entre os pares (nula, assimétrica ou mútua). O conteúdo relacional diz respeito à substância da razão para os links ocorrerem. Esse conteúdo substancial é uma construção analítica criada com o objetivo de entender as razões e significados de uma relação entre pontos de vista subjetivos dos atores como, por exemplo, a relação de amizade. Finalmente, um nível de análise deve ser estabelecido, o qual é caracterizado pelas medidas, métricas e métodos utilizados pelo pesquisador.

Quatro níveis distintos de análise são frequentes: i) a rede social egocêntrica, que consiste na análise de um ator principal (ego) e de todos os atores com os quais ele se relaciona (alter-egos); ii) a rede social diádica, caracterizada pela análise entre pares de atores; iii) relações triádicas, ou seja, entre tríades de atores; iv) a rede social completa, em que pesquisadores utilizam a informação entre cada relação existente e entre cada um dos atores para representar e explicar as relações estruturais da rede social inteira.

Uma vez que a rede social encontra-se estabelecida, canais de comunicação e colaboração existentes podem tanto ser potencializados quanto utilizados com outras finalidades. Por meio do estudo dessas redes sociais é possível entender fenômenos sociais, estratégias de entrada no mercado e até mesmo oportunidades não exploradas pelos atores formadores da rede social. 
Mizruchi (2006), apresenta um panorama da literatura e avanços na análise de redes sociais nas áreas de centralidade e poder, subgrupos da rede e relações inter-organizacionais e discute as questões controversas no campo, tais como a relação entre análise de redes e a teoria da escolha racional, o papel das normas e da cultura e a questão da agência humana.

A análise de redes sociais por meio de suas métricas permite verificar, entre outras características, os principais agentes mantenedores da rede social e propagadores das informações ou motivadores de ações de colaboração (MARTELETO, 2001). Para tanto, algumas análises essenciais são as relacionadas ao grau dos nós, à densidade da rede social e às medidas de centralidade.

Scott (2007) sumariza a teoria e prática da análise de redes sociais aplicadas às ciências sociais e documenta as diretrizes dessa análise explicando os conceitos básicos, revisando os principais softwares disponíveis e apresentando as métricas frequentemente utilizadas na análise de redes sociais, entre as quais podem ser citadas: medidas de centralidade, densidade, grau dos nós, distâncias, caminhos, diâmetros, ciclos, componentes, pontes, pontos de corte, árvores, distâncias geodésicas, clusters, núcleos, cliques e técnicas de análise gráfica.

Em um grafo com arestas simétricas, o grau de cada vértice é dado pelo número de arestas que se conectam a ele. A identificação dos cutpoints ou pontos de corte também é importante para a localização dos atores que desempenham papéis de conectores entre blocos distintos do grafo (SCOTT, 2007, p. 107-8). Na prática, esses atores são responsáveis por conectar blocos de cooperação ou até mesmo agentes que tenderiam a ficar isolados do restante da rede social. Eles atuam como o único caminho ou conexão entre um determinado agente ou grupo de agentes e o restante da rede social.

Segundo Scott (2007, p. 71), a densidade de um grafo é definida pelo número de arestas do grafo, expressas como uma proporção do número máximo de arestas possíveis, considerando-se todos os vértices. A fórmula para o cálculo da densidade é $m /[n(n-1) / 2]$, em que $m$ é o número de arestas e $n$ é o número de vértices.

A medida betweenness centrality ou centralidade de intermediação, uma métrica relacionada à centralidade dos atores em relação à rede social, representa a relevância de atores que possibilitam o fluxo de informação dos maiores grupos e, 
portanto, apresentam as maiores conectividades com a rede social por meio de um menor número de cliques ou passos (FREITAS; PEREIRA, 2005). De acordo com Scott (2007), o conceito mede a intensidade com que um determinado ponto situa-se "entre" vários outros pontos no gráfico: um ator de grau relativamente baixo pode desempenhar um importante papel mediador e assim ser muito central à rede social.

\section{RESULTADOS E DISCUSSÕES}

\subsection{Utilização das TIC}

Entre os estabelecimentos entrevistados na atual pesquisa, $72,73 \%$ são drogarias. Das 66 empresas, 10,61\% participam de rede associativista, 30,31\% possuem ou são filiais e 16,68\% participam de redes privadas com mais de 10 filiais. Com a chegada das grandes redes privadas na região estudada, os proprietários que não participam de redes associativistas disseram que, comparando custos e benefícios, participar desse modelo de comércio e gestão não é mais tão atrativo, uma vez que o principal benefício que era o acesso a mercadorias com preços mais acessíveis, não é mais suficiente para superar os preços e a política de descontos adotada pelas grandes redes privadas. A principal estratégia passou a ser a fidelização do cliente por meio do atendimento customizado.

As empresas entrevistadas relataram que as grandes redes privadas de farmácias e drogarias - que conseguem melhores condições de compra diretamente das indústrias, repassando descontos para os clientes -, em sua maioria com matriz e origem fora do estado, são as principais responsáveis pelo fenômeno descrito como "concorrência desleal" - fenômeno que afeta os microempresários e é visto como uma das principais dificuldades de atuação no setor, acompanhado dos altos encargos tributários. Juntos, eles são as causas da alta rotatividade de proprietários nas farmácias e drogarias e de um expressivo número de falências. Durante a presente pesquisa foram identificados quatro estabelecimentos comerciais (farmácias e drogarias) que haviam recentemente encerrado suas atividades. Entre os estabelecimentos entrevistados observou-se que cerca $31,82 \%$ tem menos de cinco anos ou trocaram de proprietário nesse período. Foi calculada uma média de 
12,38 anos de funcionamento dos estabelecimentos pesquisados com desviopadrão de 9,98 anos.

De um modo geral a utilização de recursos de TIC com a finalidade de melhorar o atendimento ao consumidor nas farmácias e drogarias pesquisadas ainda é modesta. A principal queixa dos entrevistados é que, no dia-a-dia, não há tempo suficiente para alimentar o computador com informações de todos os clientes, e muitas informações acabam se perdendo. Foi observado também, durante a ação de observação direta e durante o tempo de permanência nas lojas para a execução das entrevistas, que principalmente clientes idosos são os que mais necessitam que o estabelecimento conheça seus hábitos sendo cativados quando o atendimento é realizado em um nível mais pessoal.

Nas 66 empresas entrevistadas observou-se uma média de 4,71 computadores por empresa com um desvio padrão de 3,01, sendo que o estabelecimento comercial com mais computadores possui 15 e o com menos possui apenas um. Foi observado que esse número está mais relacionado com o tamanho físico, a estrutura e os serviços (vendas, delivery ou manipulação) prestados pelo estabelecimento do que com o número total de filiais da empresa. Já no quesito página na internet, a relação é oposta: empresas com mais filiais são maioria.

O percentual de empresas entrevistadas que possuem página na internet ainda é modesto $(22,73 \%)$, reflexo de uma clientela que ainda não possui o hábito de utilizar o comércio eletrônico ou que ainda não tem acesso facilitado e constante à internet, de acordo com depoimentos dos proprietários entrevistados. Enquanto distribuidoras mantém comunicação com as farmácias e drogarias basicamente por meio de representantes comerciais, softwares de pedido eletrônico de mercadorias e e-mail (correio eletrônico), os estabelecimentos comerciais entrevistados mantêm contato entre si e com os clientes utilizando o telefone ou contato presencial. 
Tabela 2 - Utilização e função das páginas na internet entre as empresas entrevistadas.

\begin{tabular}{lcc}
\hline $\begin{array}{l}\text { Finalidade da Página na } \\
\text { Internet }\end{array}$ & $\begin{array}{c}\text { Frequência } \\
\text { Absoluta }\end{array}$ & Frequência Relativa [\%] \\
\hline Comercio Online & 3 & 4,55 \\
Promoção de Ofertas & 4 & 6,06 \\
Institucional & 8 & 12,12 \\
Não Possuem Página & 51 & 77,27 \\
\hline Total & 66 & 100,00
\end{tabular}

Os estabelecimentos comerciais estudados conectam-se à internet utilizando banda larga por meio da infra-estrutura de cabeamento telefônico com tecnologia DSL (Digital Subscriber Line), predominantemente. Esse recurso é fundamental para comunicação entre filiais, para a prestação de contas junto aos órgãos de controle e fiscalização, para a utilização de softwares de pedido eletrônico de mercadorias junto aos distribuidores e para usufruir do suporte técnico remoto (a distância) que as empresas desenvolvedoras de software adotam.

Todas as empresas entrevistadas utilizam algum software de automação comercial e emissão de relatórios para o SNGPC. Foram identificadas 12 empresas fornecedoras dessas soluções em TIC. Três delas são responsáveis por atender a aproximadamente $60 \%$ da demanda desses estabelecimentos. O fornecedor de soluções em automação comercial entrevistado salienta que as ferramentas de gestão financeira disponíveis no software são as menos utilizadas, e uma grande dificuldade de seus clientes é o controle de estoque. Disse ainda que apesar da empresa oferecer treinamentos gratuitos, apenas parte dos clientes se interessa em participar, sendo baixa a frequência nos treinamentos. Ele explicou também que as frequentes mudanças na legislação do setor são, por um lado, um entrave para o desenvolvimento de novas soluções - uma vez que é sempre necessário revisar ou reestruturar uma ferramenta já existente - e, por outro lado, um empecilho para que as empresas atuem com comércio eletrônico, já que são muitas as exigências e cuidados que devem ser tomados para se estabelecer uma loja virtual.

Durante a ação de observação direta, a geração do respectivo relatório e o envio para o órgão fiscalizador foi acompanhado. Soluções de automação comercial ou softwares específicos para o propósito foram utilizados em todo o processo, desde a chegada do produto no estabelecimento comercial até a comercialização e 
prestação de contas às agências fiscalizadoras por meio da internet. O farmacêutico é o responsável por esse processo e, com o objetivo de torná-lo o mais eficiente possível, recorre a ferramentas de TIC a todo instante, utilizando até mesmo soluções diferentes das já adotadas para a automação comercial. Dos estabelecimentos entrevistados, 10,61\% utilizam um software diferente do adotado para automação comercial para emitir ou auxiliar na elaboração dos relatórios para o SNGPC.

Esses recursos tecnológicos são os grandes facilitadores da integração de dados. Eles são ferramentas indispensáveis na formação e manutenção das diversas relações existentes entre os funcionários das empresas do setor.

\subsection{Formação e Análise da Rede Mapeada}

Observa-se entre os alvos da presente pesquisa uma necessidade de constante troca de informações. Essa comunicação tem importância acentuada em um setor que fornece produtos e serviços essenciais à população e que convive diariamente com a descoberta de novas substâncias e tratamentos, com o desenvolvimento de novos produtos e com a proibição da comercialização de outros tantos devido à descoberta de novos e graves efeitos colaterais. Há ainda o fator logístico e a acentuada concorrência que exigem dos pontos de distribuição e de venda de medicamentos um controle preciso da demanda e dos canais fornecedores, levando-os a buscar melhores preços, menor tempo de espera entre o pedido de mercadorias e a entrega e a constante atualização dos estoques.

Diante deste cenário, o consumidor final torna-se cada vez mais crítico à medida que o acesso à informação é facilitado, seja via televisão ou via internet, e torna-se cada vez mais impaciente, exigindo dos estabelecimentos comerciais respostas rápidas e atendimento customizado. Os microempresários lutam contra a chamada "concorrência desleal" com uma abordagem customizada em relação a seus clientes. Com uma carteira de clientes menor e menos variável em relação às grandes redes privadas, os proprietários e balconistas investem seus esforços no bom atendimento e no relacionamento com seus clientes. Segundo eles, esse é o grande diferencial em relação às grandes redes privadas. "Nós pequenos, conhecemos nossos clientes, muitas vezes mantemos até relações de amizade com 
eles e isso cria um vínculo valioso entre eles e a nossa empresa", relatou um dos proprietários entrevistados.

Enquanto as grandes redes privadas investem em cartões de fidelidade - de modo a incentivar o cadastro de seus clientes em troca de descontos e, com isso, gerar históricos de compras, oferecendo também um atendimento mais customizado quando o cliente retorna ao estabelecimento -, os demais estabelecimentos atuam em um nível mais pessoal, em que cada balconista constrói sua carteira de clientes à medida que conhece as necessidades e hábitos de cada consumidor. É comum nesses estabelecimentos que os clientes sejam reconhecidos e tratados pelo nome e que, mesmo quando de passagem, parem nas lojas para uma rápida conversa com os funcionários.

Com o objetivo de atender aos seus clientes com máxima qualidade, funcionários e proprietários buscam parcerias até mesmo com seus tradicionais concorrentes. A colaboração se baseia no fato de que as micro e pequenas empresas, em vez de competirem entre si, preferem fidelizar os clientes que tenderiam a procurar as grandes redes privadas em busca de descontos. Além disso, esses estabelecimentos possuem a vantagem de, em muitos casos, estarem presentes em bairros nos quais as grandes redes privadas não se instalam, normalmente bairros considerados de periferia.

Nesse contexto as TIC possibilitam a integração principalmente entre as micro e pequenas empresas. A busca pelo atendimento fidelizador gera laços que conectam os agentes dando origem a uma rede social de informação, colaboração e sustentação frente à chamada "concorrência desleal" provocada pelas grandes redes privadas de farmácias e drogarias.

Foram identificados três cenários possíveis de interação entre os estabelecimentos. Um primeiro ocorre entre filiais. Nesses estabelecimentos a comunicação é constante e é comum que os sistemas de gestão sejam integrados de modo a possibilitar a localização física, nas diferentes lojas, de produtos demandados por um cliente ou a centralização de pedidos de produtos junto aos fornecedores de modo a conseguir descontos, devido às maiores quantidades demandadas. Para tanto, a internet, o telefone e os serviços de VolP mostraram-se ferramentas indispensáveis. 
O segundo cenário é característico das empresas que participam de redes associativistas. Nesses estabelecimentos, os proprietários pagam mensalmente para participar de uma rede associativista que compra determinados produtos em quantidade suficiente para negociar com a indústria por preços mais baixos, que podem ser repassados para os clientes finais em forma de desconto. Essas redes associativistas também atuam com ações de promoção no rádio, na televisão e por meio de panfletos. Contudo, a interação entre os estabelecimentos que compõem esse modelo de rede associativista não é tão frequente.

O terceiro cenário que surge é o formado pela colaboração entre empresas concorrentes que, estabelecidas em distâncias geográficas relativamente pequenas, umas em relação às outras, cooperam para garantir a fidelização dos clientes que já compõem sua carteira ou que moram ou trabalham nas proximidades do estabelecimento. Se, por exemplo, um cliente que possui o hábito de comprar em um estabelecimento hipotético $X$ procura um produto que está em falta na loja e nas distribuidoras ou indústrias, 0 estabelecimento $X$ imediatamente aciona seus contatos em busca de outra empresa que tenha o produto em estoque e compra a mercadoria a preço de mercado com o objetivo de garantir o atendimento ao seu cliente, evitando assim que ele tenha que percorrer diversas lojas até encontrar o produto almejado.

Outra forma de colaboração é a divulgação de notícias relativas a lançamentos ou à proibição da comercialização de determinados produtos, o que faz com que os estabelecimentos busquem adequar-se em tempo reduzido às novas diretrizes de mercado ou novas regulamentações estabelecidas pelos órgãos de controle e fiscalização. Quando ocorrem furtos ou outras emergências, a rede social permite a rápida disseminação da informação e possibilita que os funcionários e proprietários tomem providências, visando a resguardar-se de situações de risco.

$\mathrm{Na}$ presente pesquisa foi adotada uma estratégia de análise da rede social completa. Dados relacionais foram construídos considerando a direção das relações entre os pares como simétricas - isto é, arestas não direcionadas -, e a intensidade dos links (arestas) foi estabelecida em 3 níveis: nível 1, fraco (relações entre estabelecimentos que estão em contato por meio de uma rede associativista); nível 2. intermediário (relações de comunicação entre proprietários e funcionários de 
empresas distintas, construído na maioria dos casos sob laços de parentesco familiar ou amizade); nível 3, forte (links entre matrizes e filiais).

O mapeamento da rede social levou à construção do grafo representado na figura 3-a, com o auxílio do software para análise de redes sociais UCINET (BORGATTI et al., 2002).No grafo, cada vértice representa um estabelecimento comercial. Estabelecimentos de uma mesma cor representam matrizes e filiais de uma mesma empresa. As conexões fracas estão representadas por arestas vermelhas, as intermediárias por arestas azuis e as fortes por arestas pretas.

$\mathrm{Na}$ região inferior dos grafos da figura 3 é possível identificar quatro grupos de duas empresas que interagem apenas entre si (duplas), ou seja, possuem grau um, uma vez que apenas uma conexão é estabelecida. Dois desses grupos (o mais superior e o mais oriental) é composto por filiais de uma mesma empresa. Os outros dois grupos representam canais de cooperação entre empresas distintas. Na porção superior central do grafo é possível identificar as sete empresas que se relacionam sob modelo associativista (arestas em vermelho), sendo cinco dessas filiais de uma mesma empresa (vértices em azul-claro ligados por arestas pretas). Na porção superior esquerda encontramos 10 empresas que não se relacionam com nenhuma outra, ou seja, possuem grau zero uma vez que não estabelecem nenhuma conexão.

Figura 3 - Representação gráfica da rede social. (a) diferenciação das empresas pela cor dos vértices e da natureza de interação pela cor das arestas. (b) diferenciação das componentes conexas pela cor dos vértices.

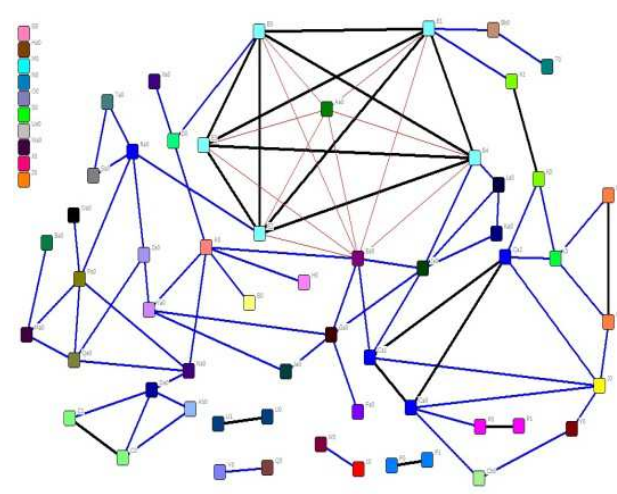

(a)

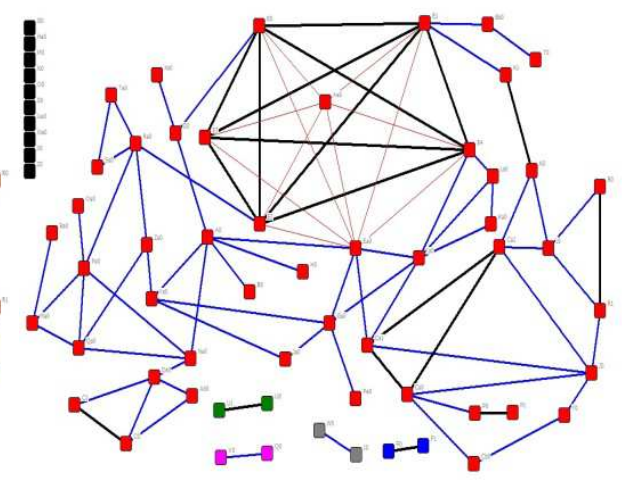

(b)

Pela análise desse grafo é possível verificar que das 66 empresas estudadas, 48 estão conectadas por meio de uma rede social de relacionamentos tanto formal 
quanto informal, potencializando a comunicação e a integração no setor, isto é, formam uma grande componente conectada em que a informação pode fluir de ponta a ponta por meio dos agentes (vértices), no caso, farmácias e drogarias.

Pode-se visualizar todas as componentes existentes diferenciadas pela cor dos vértices na figura 3-b. Em preto, os vértices com grau zero, ou seja, os que não se conectam com nenhum outro nó. Em verde, rosa, cinza e azul encontram-se os oito vértices que formam quatro componentes, cada uma com grau um. Em vermelho os 48 vértices com graus diversos que compõem a maior componente do grafo.

Para analisar a componente principal do grafo foi plotada a figura 4, na qual os vértices de graus distintos estão diferenciados por cor e os graus correspondentes estão explícitos em formato numérico a direita de cada vértice. Das 18 empresas que correspondem às componentes periféricas do grafo, 66,67\% são farmácias, o que corresponde a 70,59\% das farmácias entrevistadas e indica uma tendência das farmácias a não se integrarem tanto a redes sociais quanto as drogarias.

Figura 4 - Representação gráfica da rede social diferenciando os graus dos vértices por cor e explicitando o valor numérico à direita do respectivo vértice

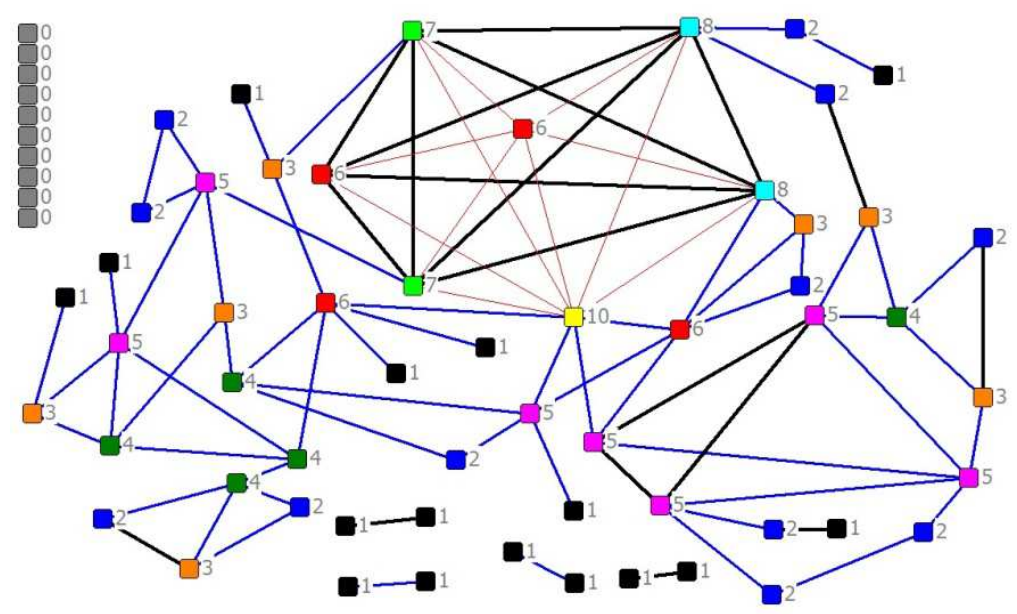

Pode-se observar que o menor grau observado no grafo é zero, o menor grau observado na componente principal (formada por 48 empresas) é um e o maior grau do grafo (vértice na região central em amarelo) é 10. 
Figura 5 - Representação gráfica da rede social explicitando os cutpoints em vermelho.

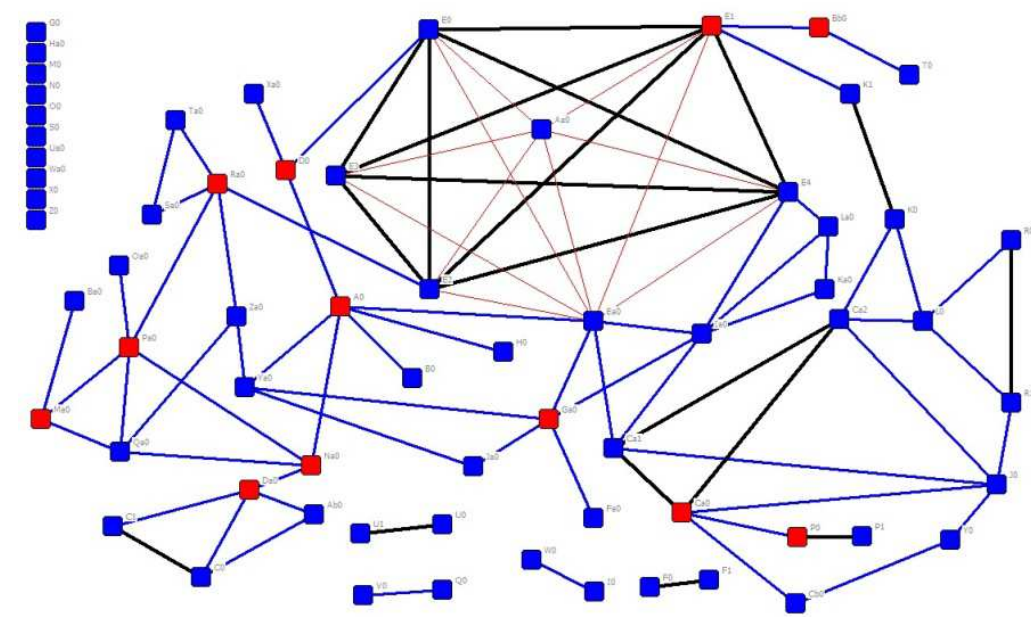

A figura 5 explicita os cutpoints ou pontos de corte do grafo, identificando-os em vermelho. É possível verificar que eles representam $18,18 \%$ dos estabelecimentos estudados e $25,00 \%$ dos estabelecimentos que compõem a principal componente do grafo, o que reforça o importante papel integrador desempenhado por esses atores, haja vista que o número de cutpoints e a centralidade desses atores em relação à rede social estão diretamente ligados à fragilidade da rede. Quanto mais dependente de agentes que atuam como pontos de corte, mais propensa a desarticulação a rede social se torna.

Para o grafo estudado, tem-se que a densidade é $4,20 \%$, o que reflete a existência de vértices isolados e de componentes com número reduzido de vértices. Se fpr considerada apenas a componente principal, a densidade passa a ser $7,62 \%$, representando um aumento de $81,53 \%$ em relação à densidade do grafo original. $A$ análise indica que a densidade da rede social pode ser aumentada significativamente caso haja esforço dos atores que compõem a componente principal do grafo em integrar as demais componentes. Além disso, é possível verificar que, mesmo na componente principal, existe uma ampla gama de conexões possíveis que ainda não foram estabelecidas e que podem ajudar a reduzir a fragilidade da rede social, minimizando o número de pontos de corte existentes no grafo. 
Figura 6 - Representação gráfica da rede social explicitando os cutpoints em vermelho, representando os vértices com tamanho proporcional ao seu grau e com os valores da medida betweenness centrality numericamente representados à direita do respectivo vértice

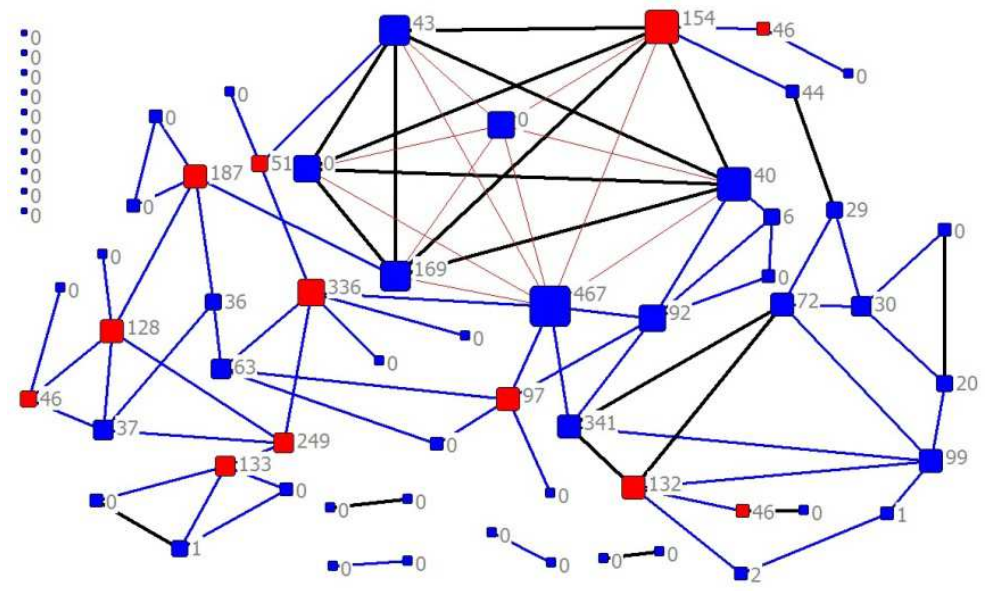

$\mathrm{Na}$ figura 6 podem-se observar vértices que possuem graus menores que outros, mas que são pontos de corte ou possuem a medida betweenness centrality mais expressiva. Por meio dessa análise é possível identificar, classificar e escolher vértices adotando critérios de relevância correspondentes às características específicas desejadas para a rede social. É possível, por exemplo, dar maior ênfase ao fomento de novas conexões por vértices que são pontos de corte, priorizando aqueles cuja relevância é maior para a rede social do ponto de vista da centralidade, o que garante maior fluxo de informação ou maior potencial de colaboração em menor tempo.

\section{CONSIDERAÇÕES FINAIS}

Observou-se que a adoção das TIC no setor transpôs a necessidade de automação comercial e consolidou-se como recurso essencial às políticas e práticas de controle e fiscalização. Os proprietários começam a dar os primeiros passos no campo da fidelização do cliente e customização do atendimento no varejo por meio das TIC. A internet começa a ser vista como aliada no processo de comunicação entre filiais e matrizes, na compra de mercadorias dos distribuidores, no comércio online e no processo de promoção da empresa e de seus produtos.

Contudo, os grandes entraves frente à utilização das TIC no setor estão relacionados às constantes alterações da legislação, às dificuldades, principalmente 
dos micro-empresários, em alimentar os sistemas com informações geradas no cotidiano da empresa e pela fraca cultura de utilização da internet e seus canais tais como websites, redes sociais, blogs, mensageiros instantâneos e e-mail pelos clientes de farmácias e drogarias para aquisição de medicamentos e produtos de perfumaria e higiene pessoal.

Recomenda-se aos proprietários investir nesses canais, até então pouco explorados, tendo em vista a popularização da internet e a acessibilidade crescente a computadores, tablets e smartphones. A utilização da internet pode se tornar aliada até mesmo entre as micro e pequenas empresas, frente à crescente concorrência estabelecida pelas grandes redes privadas de farmácias e drogarias.

Os benefícios gerados pela rede social de colaboração mapeada podem ser potencializados e até mesmo a densidade da rede social pode ser aumentada se houver esforços relativos à integração das empresas por meio das TIC.

O mapeamento da rede social gerou informações valiosas que podem ser utilizadas por fabricantes e distribuidoras para elaborar estratégias de lançamentos e divulgação de novos produtos entre seus clientes, usufruindo da estrutura de comunicação já existente e do papel articulador dos agentes centrais da rede social.

Os proprietários de drogarias e farmácias também podem usufruir desses dados entendendo como funciona a dinâmica da comunicação no setor inserida na sua realidade local e, desse modo, buscar parcerias e conexões, visando a melhorar seu acesso à informação ou consolidar sua participação como formadores de opinião no mercado. Principalmente para os microempresários que se mostraram temerosos em relação às grandes redes privadas de farmácias e drogarias, utilizar os dados gerados para fomentar parcerias entre seus pares pode ser uma alternativa ao modelo de rede associativista e uma nova vantagem competitiva dentro do setor.

Novos estudos podem focar-se no mapeamento de uma rede social mais abrangente e podem avaliar outras formas de contato e conexões existentes entre as empresas, revelando novos atores, novas conexões e retratando a rede social de forma ainda mais fidedigna à realidade. Recomenda-se cuidado especial no mapeamento das empresas e nas ações de entrevistas. Foi observado que diferentes colaboradores das empresas mantinham contatos distintos com outros 
estabelecimentos; portanto, entrevistar apenas o proprietário, o farmacêutico ou um balconista pode não ser suficiente para detalhar em profundidade a rede social existente e identificar todos os atores e seus papéis.

\section{REFERÊNCIAS}

ADAMIC, L. A., LUKOSE, R. M., PUNIYANI, A. R., HUBERMAN, B. A. Search in power-law networks. Phys. Rev., v.64, 2001.

ALBERT, R., JEONG,H., BARABÁSI, A.-L. Attack and error tolerance of complex networks. Nature, v.406, jul. 2000.

ANVISA, Agência Nacional de Vigilância Sanitária. Disponível em: <http://www.anvisa.gov.br>. Acesso em: 26 maio 2009.

BALL, F., MOLLINSON, D., SCALIA-TOMBA, G. Epidemics with two levels of mixing. Annals of Applied Probability, v.7, n.1, p.46-89, 1997.

BORGATTI, S. P., EVERETT, M. G., FREEMAN, L. C. Ucinet 6 for windows: software for social network analysis. Havard: Analytic Tchnologies, 2002.

CALLAWAY, D. S., NEWMAN, M. E. J., STROGATZ, S. H., WATTS, D. J. Network robustness and fragility: percolation on random graphs. Phys. Rev. Lett., v.85, n.25, p.5468-5471, 2000.

CARNEIRO, Teresa Cristina Janes. Integração organizacional e tecnologia da informação: um estudo na indústria farmacêutica. 2005. 184 p. Tese. (Doutorado em Administração)- Universidade Federal do Rio de Janeiro, Instituto COPPEAD de Administração. Rio de Janeiro, 2005.

CFF. Conselho Federal de Farmácia. Disponível em: <http://www.cff.org.br>. Acesso em: 04 mar. 2010.

CHRISTOPHER, Martin. Logística e gerenciamento da cadeia de suprimentos: estratégia para redução de custos e melhoria dos serviços. São Paulo: Pioneira, 1997.

COHEN, R., EREZ, K., BEM-AVRAHAM, D., HAVLIN, S. Resilience of the internet to random breakdowns. Phys. Rev. Lett., v.85, n.21, p.4626-4628, 2000.

FEBRAFAR. Federação Brasileira das Redes Associativistas de Farmácias.

Disponível em: <http://www.febrafar.com.br>. Acesso em: 23 mar. 2010.

FREEMAN, Linton C. The development of social network analysis. Vancouver: Empirical Press, 2004. 
FREITAS, M. C., PEREIRA, H. B. B. Contribuição da análise de redes sociais para o estudo sobre os fluxos de informações e conhecimento. ENCONTRO NACIONAL DE ENSINO E PESQUISA EM INFORMAÇÃO, 6., 2005. Anais... 2005.

GOOGLE EARTH (versão 5.1.3533.1731) Software: mountain view. CA: Google Inc, 2009.

IMS HEALTH. Retail drug monitor. Disponível em: <http://www.imshealth.com>. Acesso em: 26 maio 2009.

KEELING, M. J. The effects of local spatial structure on epidemiological invasion.

Proc. R. Soc. B, v.266, p.859-867, 1999.

KLEINBERG, J. M. Authoritative sources in a hyperlinked environment. J. ACM, v.46, n.5, p.604-632, 1999.

KNOKE, D., Yang, S. Social network analysis. 2. ed. London: SAGE Publications, 2008.

KUPERMAN, M., ABRAMSON, G., Small world effect in an epidemiological model.

Phys. Rev. Lett., v.86, n.13, p.2909-2912, 2001.

MACHLINE, Claude; AMARAL JÚNIOR, José Bento C. Avanços logísticos no varejo nacional: o caso das redes de farmácias. Revista de Administração de Empresas, v.38, n.4, p.63-71, out./dez. 1998.

MARTELETO, R. M. Análise de redes sociais: aplicação nos estudos de transferência de informação. Ciência da Informação, v. 30, n. 1, 2001, p. 71-81, jan./abr. 2001.

MIZRUCHI, M. S. Análise de redes sociais: avanços recentes e controvérsias atuais. Rev. adm. empres. [online], v.46, n.3, p.72-86, 2006.

MOORI, R. G., et al. Alinhamento estratégico informacional na indústria de medicamentos. FACES R. Adm., Belo Horizonte, v.6, n.1, p. 79-92, jan./abr. 2007.

NEWMAN, M., BARABÁSI, A.-L., WATTS, D. J. The structure and dynamics of networks. New Jersey: Princeton University Press, 2006.

PASTOR-SATORRAS, R., VESPIGNANI, A. Epidemic spreading in scale-free networks. Phys. Rev. Lett., v.86, n.14, p.3200-3203, 2001.

PORTAL SAÚDE. Ministério da Saúde. Disponível em: <http://portal.saude.gov.br/>. Acesso em: 27 Mai. 2010.

SCOTT, John. Social network analysis: a handbook. 2. ed. London: SAGE Publications, 2007. 
TELELISTAS.NET. Lista telefônica: 102 online: Brasil. Disponível em: <http://telelistas.net/>. Acesso em: 23 mar. 2010.

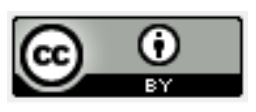

Artigo recebido em 11/05/2011 e aceito para publicação em 20/12/2011. 